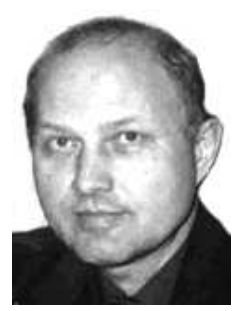

КОСТИКОВ

Юрий Васильевич (МГТУ им. Н.Э. Баумана)

KOSTIKOV

Yuriy Vasil'evich

(Moscow, Russian Federation, Bauman Moscow State

Technical University)

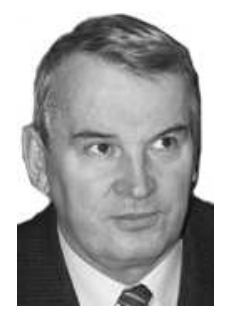

ТИМОФЕЕВ

Геннадий Алексеевич (МГТУ им. Н.Э. Баумана)

TIMOFEEV

Gennadiy Alekseevich (Moscow, Russian Federation,

Bauman Moscow State

Technical University)

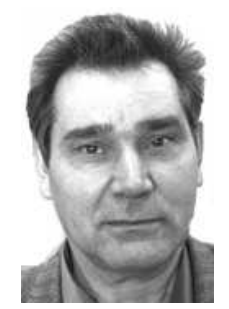

ФУРСЯК

Федор Иосифович (МГТУ им. Н.Э. Баумана)

FURSYAK

Fedor Iosifovich

(Moscow, Russian Federation, Bauman Moscow State Technical University)
Кинематическая погрешность и мертвый ход волновых зубчатых передач внешнего деформирования

\author{
Ю.В. Костиков, Г.А. Тимофеев, Ф.И. Фурсяк
}

Волновые зубчатые передачи с генераторами волн внешнего деформирования являются одной из малоисследованных конструктивных разновидностей волновых передач, позволяющих получить высокоточный одноили многодвигательный электромеханический привод.

В научной литературе, кроме исследований авторов статьи, практически отсутствуют публикации об особенностях этих волновых передач.

В данной статье представлены результаты экспериментальных исследований кинематической погрешности волновых зубчатых передач с генераторами волн внешнего деформирования. Исследовано влияние геометрических параметров волнового зацепления (угла защепления и угла облегания) на составляющие суммарной кинематической погрешности: местную кинематическую погрешность, циклическую погрешность и ошибку мертвого хода.

Результаты исследования расширяют знания о достоинствах этих волновых передач в сравнении с передачами внутреннего деформирования. При использовании в промышленности этого вида волновых передач можно получить интересные конструктивные решения приводов с высокими качественными показателями по кинематической точности и крутильной жесткости.

Ключевые слова: волновая зубчатая передача, генератор волн внешнего деформирования, гибкое и жесткое зубчатые колеса, кинематическая точность, погрешность мертвого хода.

\section{Kinematic error and backlash in wave gears with external deformation}

\section{Y.V. Kostikov, G.A. Timofeev, F.I. Fursyak}

Wave gears with external deformation wave generators are one of the scantily studied design varieties of harmonic gear drives suitable for use in high-precision single or multi-motor electromechanical drives. There are few publications in the scientific literature on the features of such wave gears except those written by the authors. This paper presents the results of experimental study of kinematic errors in wave gears with wave generators of external deformation. The effect of the geometric parameters of the wave gearing (the pressure angle and the angle of encirclement) on the components of the total kinematic error, that is, the local kinematic error, cyclic error and backlash error is studied. The results of this study extend our knowledge of the advantages of these wave gears over the gears with internal deformation. The use of this type of wave gears in industry may result in interesting designs of drives with high kinematic accuracy and torsion rigidity. 
Keywords: wave gear, external deformation wave generator, flexible and rigid gears, kinematic precision, backlash accuracy.

Узвестно, что точность воспроизведения требуемых законов движения электромеханических приводов определяется точностными характеристиками их исполнительных механизмов. Как правило, это зубчатые передачи различных типов и конструкций, которые можно разделить на два класса - с жесткими зубчатыми колесами (многоступенчатые эвольвентные цилиндрические передачи, конические, планетарные и др.) и с гибкими, изменяющими свою форму, зубчатыми колесами волновые передачи [1-9]. Конструктивные возможности нового вида волновых зубчатых передач внешнего деформирования определяют перспективность их использования для повышения качественных показателей исполнительных механизмов быстродействующих электромеханических приводов [10, 11].

Существующие методики расчета кинематической погрешности зубчатых передач (например, [12] и др.) применимы к передачам с жесткими зубчатыми колесами, так как они не учитывают специфику кинематики многопарного волнового зацепления в передачах с гибкими зубчатыми колесами. Поэтому экспериментальные методы определения влияния различных параметров волнового зацепления на его точностные характеристики являются наиболее достоверными [13, 14 и др.].

Настоящие экспериментальные исследования были проведены с целью выявления влияния условий деформирования гибкого колеса (угла облегания) и геометрических параметров зацепления волновой зубчатой передачи внешнего деформирования (угла зацепления) на ее кинематическую точность. Конструкция волновой передачи внешнего деформирования с гибким колесом 5, выполненным в виде тонкостенной оболочки, жестко присоединенной к корпусу 1 показана на рис. 1. Деформирующие кольца 2 генератора волн создают зацепление зубчатого венца гибкого колеса 5 с жестким колесом 3 в двух диаметрально противоположных зонах по малой оси деформации. Вращательное движение от электродвигателя 8 через зубчатую пару колес преобразуется генератором волн 2, 6, 7, во вращательное движение выходного вала 4. Деформирующие кольца 2 совместно с подшипниками 7 собраны на трех эксцентриковых валах 6 так, что образуют два механизма параллельных кривошипов, работающих в противофазе. При вращении трех эксцентриковых валов 6 на сдеформированном гибком колесе 5 создаются две бегущие волны внутреннего зацепления с жестким колесом 3. При этом деформирующие кольца 2 совершают поступательное движение по круговым траекториям с радиусом, равным межосевому расстоянию волновой зубчатой передачи. Использование механизма параллельных кривошипов, как генератора волн, позволяет создать многодвигательный привод, не требующий дополнительной кинематической цепи для установки датчиков обратной связи 9. Для сокращения осевых габаритов в волновых зубчатых передачах применяется гибкое колесо-кольцо, в которых используют два вида генератора волн: балочковый и кольцевой. Особенности конструкции волновой зубчатой передачи внешнего деформирования с гибким колесом-кольцом и балочковым генератором волн подробно рассмотрены в [14].

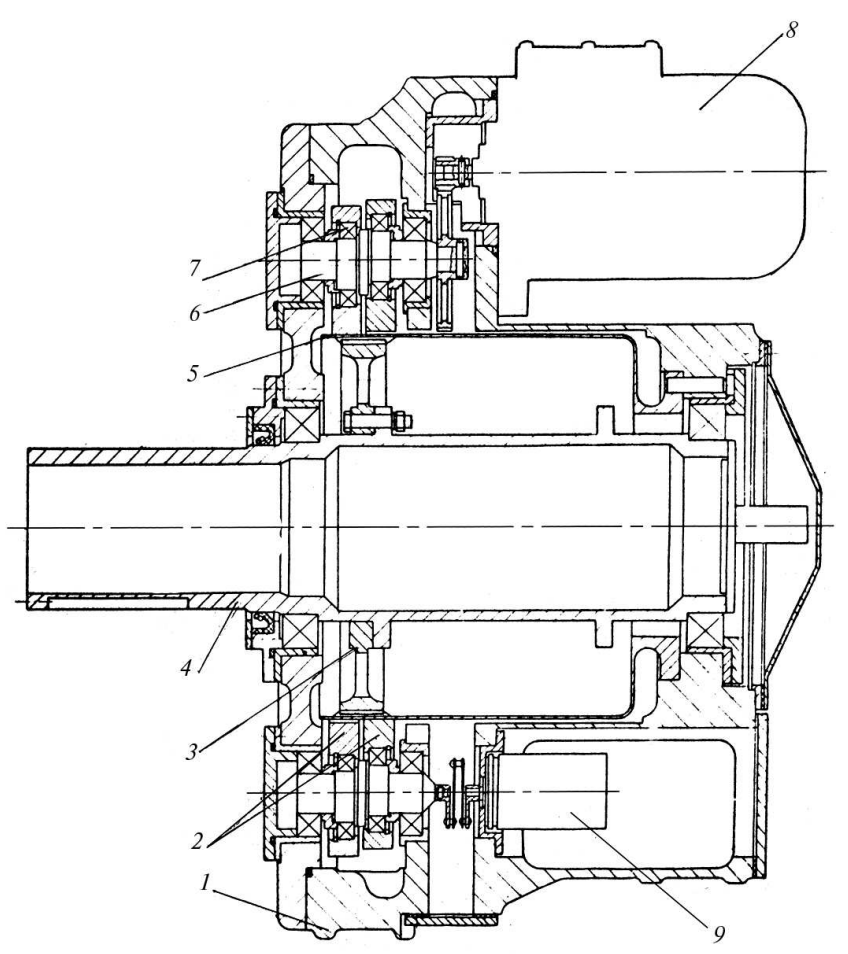

Рис. 1. Волновая передача с генератором волн внешнего деформирования 
Конструкция более технологичного кольцевого генератора волн изображена на рис. 2. Здесь гибкое колесо-кольцо 6 в двух диаметрально противоположных зонах по малой оси деформации находится в зацеплении с двумя жесткими колесами 13 , и 14, причем жесткое колесо 13 составляет с гибким колесом волновую передачу, а жесткое колесо 14 образует с ним волновую зубчатую муфту. Выходной вал 5, жестко соединенный с колесом 13 посажен в корпус редуктора на двух подшипниках 4 (на рис. 2 показан один).

Упорные кольца 3 и 12 фиксируют от осевых перемещений гибкое колесо-кольцо 6.

Деформирующие кольца 7 и 11, собранные посредством подшипников 2, 9 и 10 на трех эксцентриковых валах 1 и 8 образуют кольцевой генератор волн. Геометрические параметры указанных волновых передач рассчитывались по методике [11], разработанной на кафедре «Теория механизмов и машин» МГТУ им. Н.Э. Баумана. Для уменышения влияния погрешностей изготовления и сборки обработка деформирующих колец генератора волн осуществлялась с одной установки и их сборка производилась в одном корпусе. В качестве параметров, влияющих на кинематическую погрешность волновых зуб-

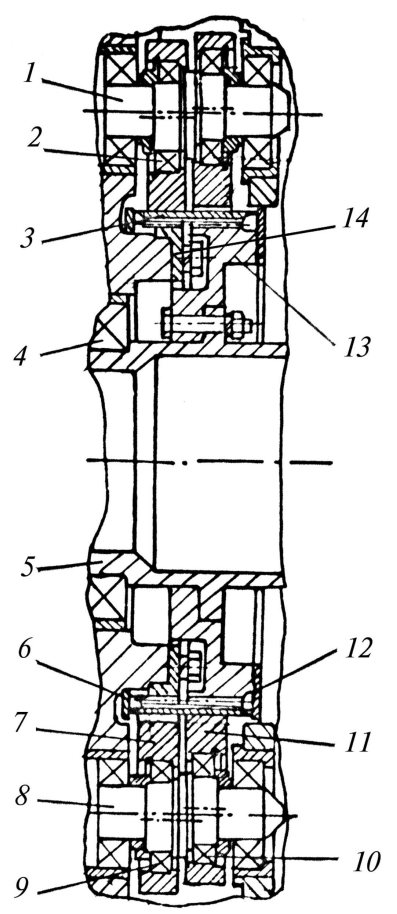

Puc. 2. Волновая передача с гибким колесом-кольцом

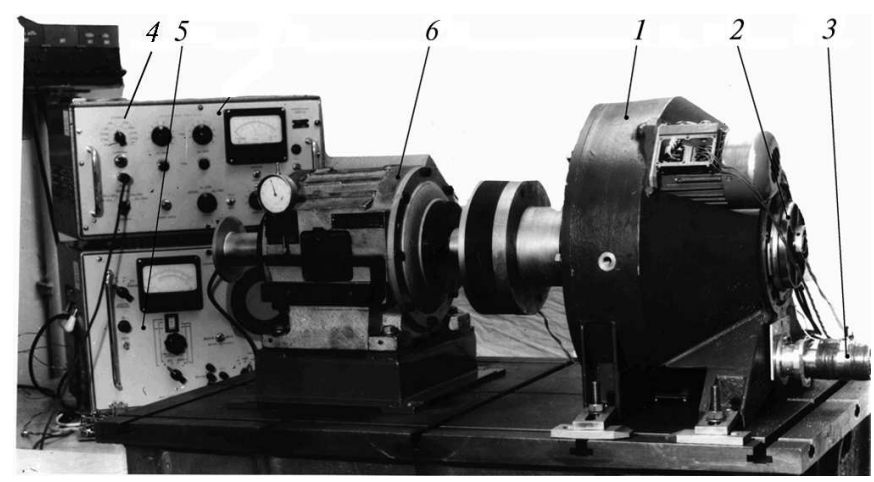

Рис. 3. Испытательный стенд

чатых передач внешнего деформирования, исследовались величина угла облегания $\beta=45^{\circ}, \beta=$ $=60^{\circ}$ и угла зацепления $\alpha_{w}=10^{\circ}, \alpha_{w}=20^{\circ}$.

Кинематическая погрешность редукторов исследовалась индуктивно-амплитудным методом на стенде, фотография которого приведена на рис. 3. Механическая редукция исследуемого редуктора 1 сравнивалась с эталонной электрической редукцией между многополюсным воздушным трансформатором ИПУ-5А 2, установленным на выходном валу, и синусно-косинусно вращающимся трансформатором 5БВТ-11 3, кинематически связанным с входным валом. Электрический сигнал рассогласования, возникающий при расфазировании индукционных преобразователей угла ИПУ-5А и 5БВТ -11 , пропорциональный изменению мгновенного передаточного отношения редуктора, регистрировался комплексом аппаратуры, состоящей из измерительного усилителя 4 типа У2-6, генератора сигналов ГЗ-39 5 и синхронного детектора. Характер изменения кинематической погрешности записывался на шлейфовом осциллографе $\mathrm{K}-12-22$. Ступенчатое нагружение редуктора крутящим моментом $M=$ $=0 \ldots 160 \mathrm{H} \cdot$ м осуществлялось с помощью порошкового тормоза 6 типа ПТ-40М. Высокочастотная электрическая редукция, бесконтактная связь и малая инерционность индуктивных преобразователей угла в комплексе с усилительной, измерительной и регистрирующей аппаратурой с высокой разрешающей способностью обеспечили погрешность измерения до 5". Исследования кинематической погрешности проводились в установившемся режиме за полный оборот выходного вала с последующим реверсом его вращения, при ступенчатом изменении нагрузки на выходном 
валу $M_{\text {кр }}=0 \ldots 160 \mathrm{H} \cdot$ м. Осциллограммы записи характера изменения кинематической погрешности (рис. 4, 5) позволили проанализировать изменения всех составляющих кинематической погрешности:

$F_{\Sigma}$ - суммарная кинематическая погрешность - наибольшая алгебраическая разность значений кинематической погрешности передачи за полный цикл изменения относительного положения зубчатых колес, включая прямое и обратное вращение;

$f_{\text {ir }}$ - циклическая погрешность - алгебраическая разность значений циклических погрешностей в пределах полного изменения относительного положения зубчатых колес без реверса вращения выходного звена;

$\Delta \varphi$ - ошибка мертвого хода - алгебраическая сумма люфтов в кинематических парах и упругих перемещений соответствующих элементов передачи, приведенные к ведомому валу и определяемая, как дополнительный угол поворота ведомого звена при неподвижном ведущем или реверсе его вращения. Результаты исследований приведены в таблице.

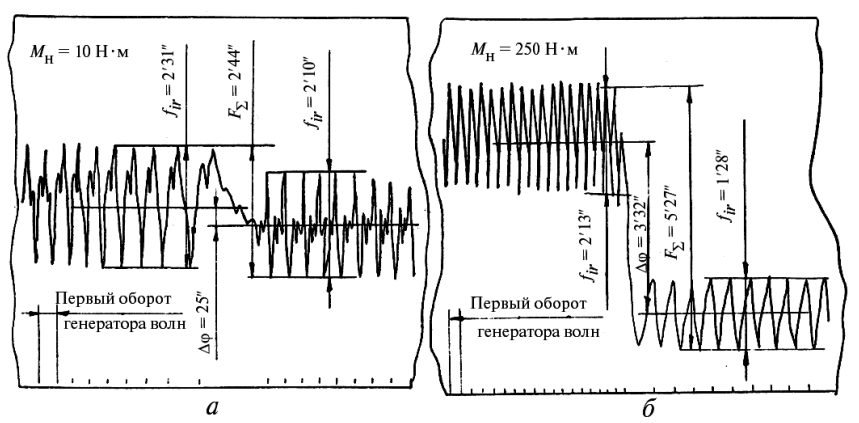

Puc. 4. Фрагменты осцилограмм кинематической погрешности редуктора при нагрузе: $a-10 \mathrm{H} \cdot \mathrm{M} ; \sigma-250 \mathrm{H} \cdot \mathrm{M}$
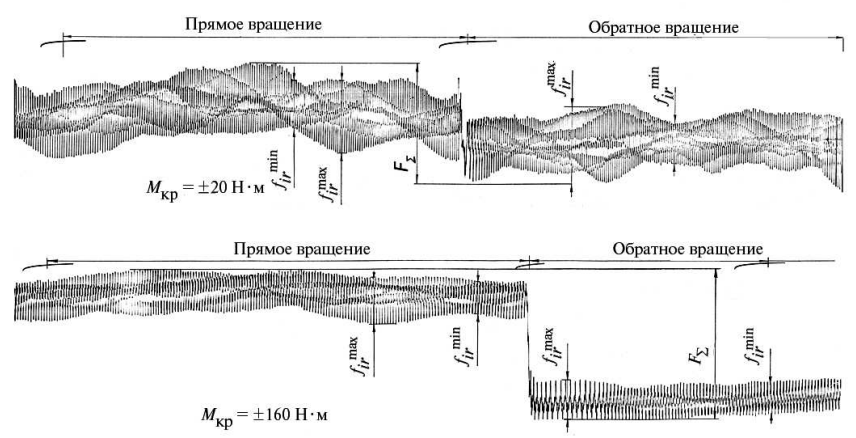

Puc. 5. Осцилограмма кинематической погрешности за полной оборот выходного вала с реверсом

Численные значения погрешностей
\begin{tabular}{|l|c|c|c|c|c|}
\hline \multicolumn{1}{|c|}{ Погрешность } & $\begin{array}{c}\text { Обо- } \\
\text { значе- } \\
\text { ние }\end{array}$ & \multicolumn{2}{|c|}{$\begin{array}{c}\text { Прямое враще- } \\
\text { ние, Н·м }\end{array}$} & \multicolumn{2}{|c|}{$\begin{array}{c}\text { Обратное вра- } \\
\text { щение, Н·м }\end{array}$} \\
\cline { 3 - 6 } & \pm 20 & \pm 160 & \pm 20 & \pm 160 \\
\hline $\begin{array}{l}\text { Суммарная ки- } \\
\text { нематическая } \\
\text { погрешность }\end{array}$ & $F_{\Sigma}$ & $2^{\prime} 55^{\prime \prime}$ & $4^{\prime} 00^{\prime \prime}$ & $2^{\prime} 55^{\prime \prime}$ & $4^{\prime} 00^{\prime \prime}$ \\
\hline $\begin{array}{l}\text { Максимальная } \\
\text { циклическая по- } \\
\text { грешность }\end{array}$ & $f_{i r}^{\max }$ & $2^{\prime} 03^{\prime \prime}$ & $1^{\prime} 19^{\prime \prime}$ & $2^{\prime} 11^{\prime \prime}$ & $1^{\prime} 05^{\prime \prime}$ \\
\hline $\begin{array}{l}\text { Минимальная } \\
\text { циклическая по- } \\
\text { грешность }\end{array}$ & $f_{i r}^{\min }$ & $1^{\prime} 19^{\prime \prime}$ & $55^{\prime \prime}$ & $1^{\prime} 08^{\prime \prime}$ & $44^{\prime \prime}$ \\
\hline
\end{tabular}

\section{Выводы}

1. Волновые передачи внешнего деформирования с расчетными параметрами являются безлюфтовыми.

2. Увеличение суммарной кинематической погрешности при повышении нагрузки обусловлено появлением и возрастанием ошибки мертвого хода.

3. Многопарность волнового зацепления под нагрузкой обеспечивает безлюфтовость зацепления и уменьшение местной кинематической погрешности за счет изменения формы деформированного гибкого колеса и увеличения многопарности волнового зацепления.

4. Увеличение угла облегания гибкого колеса генератором волн от $\beta=45^{\circ}$ до $\beta=60^{\circ}$ без нагрузки на выходном валу не влияет на суммарную кинематическую погрешность и ошибку мертвого хода, а при нагружении выходного вала уменьшает величину суммарной кинематической погрешности до $20 \%$ и местной кинематической погрешности до $30 \%$.

5. Уменьшение угла зацепления с $\alpha_{w}=20^{\circ}$ до $\alpha_{w}=10^{\circ}$ практически не влияет на величину кинематической погрешности, но снижает ошибку мертвого хода на $15 . . .35 \%$.

\section{Литература}

1. Каталог Harmonic Drive LLC. Available at: http://www. harmonicdrive.net/. Дата обращения 15.04.2013.

2. Куцоконь В.А., Шевченко-Грабский И.В. Расчет статических моментов и мертвых ходов в кинематических цепях точных приборов. Л.: Машиностроение, 1968. 147 с.

3. Люминарский И.Е., Люминарский С.Е. Расчет кинематической погрешности волновой зубчатой передачи как упругой системы с односторонним контактом звеньев // Известия высших учебных заведений. Машиностроение. 2008. № 8. С. 9-19.

4. Иванов М.Н. Волновые зубчатые передачи. М.: Высшая школа, 1981. $183 \mathrm{c.}$

5. Клеников С.С., Сергеев В.С. К вопросу определения зазоров между зубьями колес нагруженной волновой передачи // Тезисы докладов V научно-технической конференции молодых ученых и специалистов МосавтоЗИЛа. М., 1977. С. 123-124. 
6. Фурсяк Ф.И., Тимофеев Г.А., Костиков Ю.В. Волновые редукторы с генератором волн внешнего деформирования // Вестник машиностроения. 1977. № 1. С. 71-74.

7. Шувалов С.А., Попов П.К., Финогенов В.А. Характеристики точности и жесткости волновых зубчатых передач // Известия высших учебных заведений. Машиностроение. 1970. № 6. C. $56-61$.

8. Костиков Ю.В., Тимофеев Г.А., Фурсяк Ф.И. Оценка точности волновых редукторов // Депонированные рукописи ВИНИТИ. 1981. № 7.18 с.

9. Попов П.К., Фирсаев А.Ф., Шувалов С.А. Математическая модель процесса возникновения кинематической ошибки в волновой зубчатой передаче // Труды МВТУ. 1978. № 287. Прочность и надежность деталей машин. С. 50-55.

10. А. с. 541057 CCCP, МКИ F16H 1/00. Б.И. Волновая передача / В.Б. Тарабарин, Г.А. Тимофеев. 1976. № 48.

11. Конструкции и геометрический расчет волновых зубчатых передач / Гавриленко В.А., Скворцова Н.А., Ю.И. Семин и др. // Труды МВТУ. 1978. № 291. Вып. 8. Теория механизмов. Под ред. К.Ф. Фролова, Н.А. Скворцовой. С. 22-33.

12. Павлов Б.И. Механизмы приборов и систем управления. Л.: Машиностроение. 1972, 232 с.

13. Семин Ю.И., Фурсяк Ф.И. К вопросу определения мертвого хода волновой малоинерционной передачи // Известия высших учебных заведений. Машиностроение. 1968. № 5. C. $19-22$.

14. Костиков Ю.В., Тимофеев Г.А., Фурсяк Ф.И. Исследование кинематической точности волновых зубчатых передач внешнего деформирования // Известия высших учебных заведений. Машиностроение. 2012. № 6. С. 18-24.

\section{References}

1. Katalog Harmonic Drive LLC [Catalog of Harmonic Drive LLC]. Available at: http://www.harmonicdrive.net/ (accessed 15 April 2013).

2. Kutsokon' V.A., Shevchenko-Grabskii I.V. Raschet staticheskikh momentov i mertvykh khodov v kinematicheskikh tsepiakh tochnykh priborov [Calculation of the static moments and the dead moves in the kinematics chain of precision instruments]. Leningrad, Mashinostroenie publ., 1968. 147 p.

3. Liuminarskii I.E., Liuminarskii S.E. Raschet kinematicheskoi pogreshnosti volnovoi zubchatoi peredachi kak uprugoi sistemy s odnostoronnim kontaktom zven'ev [The calculation of kinematic error of the wave gear as an elastic system with unilateral contact links]. Izvestiya Vysshikh Uchebnykh Zavedenii. Mashinostroenie [Proceedings of Higher Educational Institutions. Machine Building]. 2008, no. 8, pp. 9-19.

4. Ivanov M.N. Volnovye zubchatye peredachi [The wave gear]. Moscow, Vysshaia shkola publ., 1981. 183 p.

5. Klenikov S.S., Sergeev V.S. K voprosu opredeleniia zazorov mezhdu zub'iami koles nagruzhennoi volnovoi peredachi [On the determination of the gaps between the teeth of the wheels of the loaded wave transmission] Tezisy dokladov 5 nauchno-tekhnicheskoi konferentsii molodykh uchenykh i spetsialistov MosavtoZILa [Abstracts of the 5 Scientific Conference of Young Scientists and Specialists MosavtoZILa]. Moscow, 1977, pp. 123-124.

6. Fursiak F.I., Timofeev G.A., Kostikov Iu.V. Volnovye reduktory s generatorom voln vneshnego deformirovaniia [Wave gear with external deformation of the wave generator]. Vestnik mashinostroeniia [Russian Engineering Research]. 1977, no. 1, pp. 71-74.

7. Shuvalov S.A., Popov P.K., Finogenov V.A. Kharakteristiki tochnosti i zhestkosti volnovykh zubchatykh peredach [Characteristics of accuracy and rigidity of the wave gear]. Izvestiya Vysshikh Uchebnykh Zavedenii. Mashinostroenie [Proceedings of Higher Educational Institutions. Machine Building]. 1970, no. 6, pp. 56-61.

8. Kostikov Iu.V., Timofeev G.A., Fursiak F.I. Otsenka tochnosti volnovykh reduktorov [Assessment of the accuracy of the wave gear]. Deponirovannye rukopisi VINITI [Deposited manuscripts VINITI]. 1981, no. 7, 18 p.

9. Popov P.K., Firsaev A.F., Shuvalov S.A. Matematicheskaia model' protsessa vozniknoveniia kinematicheskoi oshibki $v$ volnovoi zubchatoi peredache [Mathematical model of the emergence of kinematic error in the wave gearing]. Trudy MVTU [Proceedings of the Moscow Higher Technical School]. 1978, no. 287. Prochnost' i nadezhnost' detalei mashin [Strength and reliability of machine parts]. pp. $50-55$.

10. Tarabarin V.B., Timofeev G.A. Volnovaia peredacha [The wave transmission]. Certificate of authorship no. 541057 USSR, MKI F16H 1/00. B.I. 1976. no. 48.

11. Gavrilenko V.A., Skvortsova N.A., Semin Iu.I. Konstruktsii $i$ geometricheskii raschet volnovykh zubchatykh peredach [Geometric design and calculation of wave gear]. Trudy MVTU [Proceedings of the Moscow Higher Technical School]. 1978, no. 291, issue 8. Teoriia mekhanizmov [Theory of mechanisms], pp. 22-33.

12. Pavlov B.I. Mekhanizmy priborov i sistem upravleniia [Mechanisms of instrumentation and control systems]. Leningrad, Mashinostroenie publ., 1972. 232 p.

13. Semin Iu.I., Fursiak F.I. K voprosu opredeleniia mertvogo khoda volnovoi maloinertsionnoi peredachi [On the determination of the backlash wave transmitting low-inertia]. Izvestiya Vysshikh Uchebnykh Zavedenii. Mashinostroenie [Proceedings of Higher Educational Institutions. Machine Building]. 1968, no. 5, pp. 19-22.

14. Kostikov Iu.V., Timofeev G.A., Fursiak F.I. Issledovanie kinematicheskoi tochnosti volnovykh zubchatykh peredach vneshnego deformirovaniia [Investigation of kinematic accuracy of external deformation wave gears]. Izvestiya Vysshikh Uchebnykh Zavedenii. Mashinostroenie [Proceedings of Higher Educational Institutions. Machine Building]. 2012, no. 6, pp. 18-24.

Статья поступила в редакцию 30.04 .2013

\section{Информация об авторах}

КОСТИКОВ Юрий Васильевич (Москва) - кандидат технических наук, доцент кафедры «Теория механизмов и машин». МГТУ им. Н.Э. Баумана (105005, Москва, Российская Федерация, 2-я Бауманская ул., д. 5, стр. 1).

ТИМОФЕЕВ Геннадий Алексеевич (Москва) - доктор технических наук, профессор, зав. кафедрой «Теория механизмов и машин». МГТУ им. Н.Э. Баумана (105005, Москва, Российская Федерация, 2-я Бауманская ул., д. 5, стр. 1, е-таil: timga@bmstu.ru).

ФУРСЯК Федор Иосифович (Москва) - кандидат технических наук, доцент кафедры «Теория механизмов и машин». МГТУ им. Н.Э. Баумана (105005, Москва, Российская Федерация, 2-я Бауманская ул., д. 5, стр. 1).

\section{Information about the authors}

KOSTIKOV Yuriy Vasil'evich (Moscow) - Cand. Sc. (Eng.), Associate Professor of «Theory of Mechanisms and Machines» Department. Bauman Moscow State Technical University (BMSTU, building 1, 2-nd Baumanskaya str., 5, 105005, Moscow, Russian Federation).

TIMOFEEV Gennadiy Alekseevich (Moscow) - Dr. Sc. (Eng.), Professor, Head of «Theory of Mechanisms and Machines» Department. Bauman Moscow State Technical University (BMSTU, building 1, 2-nd Baumanskaya str., 5, 105005, Moscow, Russian Federation, e-mail: timga@bmstu.ru).

FURSYAK Fedor Iosifovich (Moscow) - Cand. Sc. (Eng.), Associate Professor of «Theory of Mechanisms and Machines» Department. Bauman Moscow State Technical University (BMSTU, building 1, 2-nd Baumanskaya str., 5, 105005, Moscow, Russian Federation). 